\title{
TWO PHASE CFD FLOW ANALYSIS OF R134a AND R1234yf REFRIGERANTS AND ITS EFFECT ON COOLING PERFORMANCE IN AN AUTOMOBILE HVAC EVAPORATOR CORE
}

\author{
Rajamanickam C S \\ Student-SMBS, VIT University, Chennai, Tamilnadu, Chennai \\ Email: raja.csrm@gmail.com, Telephone: +91-9940636597 \\ Tamilselvan $\mathrm{P}$ \\ Associate Professor-SMBS, VIT University, Chennai, Tamilnadu, Chennai \\ Email: tamilselvan.p@vit.ac.in, Telephone:+91-9894862794 \\ Anand A Samuel \\ VIT University, Chennai, Tamilnadu, Chennai \\ Email: vc@vit.ac.in, Telephone: +91-9566656780
}

\begin{abstract}
:
The purpose of this research is to conduct a two-phase fluid analysis and simulation for examining the influence of refrigerant (R134a/R1234yf) properties on cooling performance of an automobile HVAC (Heating, Ventilation and Air Conditioning) evaporator core and compare their performances. In this research, streamline deviation, static pressure, velocity magnitude, pressure co-efficiency, Reynolds number and turbulent kinetic energy play a key role in the comparison of the refrigerants R1234yf and R134a two-phase fluids. Subsequently, it was found that R134a properties were better towards the cooling performance of an automobile HVAC evaporator core.
\end{abstract}

Keywords: Refrigerant R134a, refrigerant R1234yf, cooling performance, Heating, Ventilation and Air Conditioning (HVAC) evaporator core. Two-phase fluid

\section{Research Background:}

According to Radermacher et al (2007), the refrigerant state which enters the extension device of traditional cycles for vapour compression is generally supposed to be saturated liquid. At the same time, cooling the liquid below saturation minimizes the throttling losses and maximizes performance co-efficiency. Sub-cooled liquid before the process of expansion is acquired by incorporating additional components like internal heat in single as well as two stage cycles. Moreover, sub-cooling is accomplished by an auxiliary cooling system like a thermoelectric device. A secondary system for vapour compression is referred to as mechanical sub-cooling or adopting present coolant supplies namely evaporator for condensate water. An additional cooled heat-sink heat exchanger normally denominated as sub-cooler, is adopted for obtaining cooling. A receiver of high pressure is installed between the sub-cooler and the condenser for separating liquid from vapour prior liquid executes with the help of sub-cooler.

As stated by Hrnjak et al (2008), an evaporator is incorporated for heat exchange between the refrigerant and ambient air in the air conditioning system. The orifice tube or expansion valve inserts the refrigerant which is a highly pressurized liquid, into the evaporator, extending the refrigerant. The resultant evaporator core is left to the circumstance through the large evaporator surface and routed to the interiors of the vehicle through the airflow of ventilation. A defective evaporator indicates symptoms such as poor performance of cooling and ventilation and air conditioning system failure. Causes for evaporator failure are leakage in the evaporator at the connection that occurs due to damage, blockage of pipes in the evaporator and evaporator contamination disturbing the passage of air. Refrigerant R134a is mostly an adopted refrigerant in vapour compression cycles particularly in automotive systems for air conditioning. R1234yf was developed as a substitute for R134a in mobile systems for air conditioning (Sanaye et al, 2012).

\subsection{Recognised Problems:}

Condenser sub-cooling is considered as a practical problem in daily air conditioning and refrigeration systems. A temperature difference is needed between the refrigerant in the heat exchanger and surrounding air for allowing the heat exchange to occur. In standard systems, the temperature differs around $5^{\circ} \mathrm{C}$ between the humidity at the evaporator and evaporation and $20^{\circ} \mathrm{C}$ between the outdoor temperatures and condensing at the condenser. Outcomes in a lift of temperature around $40^{\circ} \mathrm{C}$ among the condensing temperatures and evaporating which is subsequent to about 9 bar of difference in the pressure that the compressor has to give in both the R1234yf and R134a systems (Incropera et al, 2006). Therefore this research intends to focus on influence of refrigerant (R134a/R1234yf) properties on cooling performance of an automobile HVAC evaporator core.

\subsection{Aim:}

Aim of this research is to investigate in detail the influence of refrigerant (R134a/R1234yf) properties on cooling performance of an automobile HVAC evaporator core.

\subsection{Research Study:}

Following are the course of investigations to be carried for the research:

February $2017 \quad$ w w w.cirworld.com 
i. To carry out two-phase fluid analysis and simulation for examining influence of refrigerant (R134a/R1234yf) properties.

ii. To compare and contrast the performance of R134a and R1234yf properties on cooling performance of an automobile HVAC evaporator core

\section{Literature Review:}

Reasor et al (2010) examined the thermo-physical properties of refrigerant R1234yf and compared the R134a and R410A values for determining the drop-in replacement possible for R1234yf in systems developed for other refrigerants. The thermo-physical properties of R1234yf are very similar to properties of R134a, but not similar to properties of R410A. Refrigerants are simulated in sample heat exchangers. These simulations have demonstrated that R1234yf and R134a have similar outcomes for heat load and temperature of outlet refrigerant simultaneously, drop of pressure may differ. Modifications to the design of heat exchangers along with piping in such systems are needed,\%. Simulation results demonstrated that R1234yf will not be a best replacement.

Pottker and Hrnjak (2012) empirically and numerically investigated the condenser sub-cooling effect on the performance of vapour compression systems. It demonstrated that, as sub-cooling of the condenser maximizes, COP (coefficient of performance) reaches as highest as an outcome of trade-off between maximizing effects of refrigerating and compression. Thermodynamic properties linked with maximum effect of refrigerating that is latent vaporization heat and liquid specific heat are dominant for determining the maximum COP enhancement with sub-cooling of the condenser. Refrigerants with large latent vaporization heat would gain less from sub-cooling of the condenser. For a typical air conditioning system, the numerical results demonstrate that R1234yf would gain the most because of their minimal latent vaporization heat from sub-cooling of condensers when compared to R134a, R410A and R717. In contrast, COP value maximizes the subcooling which does not prove to be a strong thermodynamic property. During the comparison of R134a and R1234yf, the numerical research for the operation of a condition, the system COP maximized up to $18 \%$ for R $1234 \mathrm{yf}$ and $9 \%$ for R134a.

Lee and Jung (2012) conducted a brief comparison of R134a and R1234yf performance in a test bench for automobile applications. R134a and R1234yf performance comparison is carried out in a heat pump tester under the mobile airconditioning conditions. Outcome of the test demonstrates that the co-efficient of capacity and performance of R1234yf are up to $2.7 \%$ and $4.0 \%$ lower than that of R134a. Temperature of compressor discharge and charge amount of R1234yf is $6.5^{\circ} \mathrm{C}$ and $10 \%$ lower than R134a. It was summarized from the outcomes that R1234yf is adopted as a long term solution which is eco-friendly in MACs because of its excellent properties for environment with acceptable performance.

Gomma (2015) theoretically and experimentally conducted a thermal performance of R134a automotive air conditioning. The performance of the R134a alternatives(R1234ze, R1234yf and R152a) is characterized by low global warming potential which is less than 150. From the findings of the research, it was noted that with speed maximization in the compressor, it gives a lower COP value for all the condensing temperature values. When the temperature for condensing is maximized by $5^{\circ} \mathrm{C}$, the capacity for cooling is minimized by $9 \%$, and COP is minimized by $27 \%$. The performance of R1234yf refrigerant is most similar to R134a refrigerant in all parameters. For all evaporating and condensing values, performance of highest co-efficient is acquired for R1234e among all examined refrigerants. From thermal and environmental performance perspective, R1234yf refrigerant has the best performance among all examined refrigerants. It was also noticed that for all examined refrigerants, maximizing the condensing temperature in order to elevate power consumption in the compressor, further maximizes the load of condenser at the same rate of refrigerant flow.

Gaurav and Kumar (2015) studied about environmental sustainability of automobile system for air conditioning with Refrigerant R1234yf. This research summarizes that eco-friendly $\mathrm{R} 1234 \mathrm{yf}$ refrigerant is the replacement of $\mathrm{R} 134 \mathrm{a}$ in mobile applications for air-conditioning with temperature set for the indoors is between $20^{\circ} \mathrm{C}$ and $24^{\circ} \mathrm{C}$. This is beneficial in minimizing R1234yf flammability since it minimizes the ratio of compression, load reduction and system temperature further minimizing the refrigerant leakage and oil from the environmental system. It was noticed that cooling time minimizes with speed maximization of the blower for both refrigerants. Similar to that, maximized rate of air flow at higher speed of blower minimizes the relative humidity when the temperature for cabin modifies from $320^{\circ} \mathrm{C}$ to $240^{\circ} \mathrm{C}$. It was identified that cooling time is lesser when R1234yf refrigerant is used, in comparison with R134a and minimizes the range between $4 \%$ and $6 \%$. There is no relative modification for the blower speed effecting relative humidity of R1234yf than R134a.

\section{Research Design:}

Two-phase fluid Simulations setting for two-phase fluid analysis are as follows:

Types of the simulation are three dimensional and unsteady. Solvers in the two-phase simulation are implicit, pressure based and double precision. Multi-phase models in the two-phase simulation are 2-phase, implicit and mixture. Coupling of pressure velocity in two-phase fluid analysis is simply phase coupled. Turbulence model is k-e and mixture model. Momentum, volume friction, turbulent dissipation rate and turbulent kinetic energy of two-phase fluid analysis are prioritized. Convergence criteria for two-phase fluid analysis is $1.0 * 1.0^{-5}$

February $2017 \quad$ w w w. cirworld.com 


\begin{tabular}{|c|c|c|}
\hline $\begin{array}{c}\text { Measured or Calculated } \\
\text { Variable }\end{array}$ & Range & Uncertainty \\
\hline $\begin{array}{c}\text { Refrigeration Saturation } \\
\text { Temperature }\end{array}$ & $4^{\circ} \mathrm{C}-9^{\circ} \mathrm{C}$ & $\pm 0.2^{\circ} \mathrm{C}$ \\
\hline Surface Temperature & $4^{\circ} \mathrm{C}-21^{\circ} \mathrm{C}$ & $\pm 0.1^{\circ} \mathrm{C}$ \\
\hline Refrigerant Mass Flux & $250 \mathrm{~kg} / \mathrm{m}^{2} \mathrm{~s}$ & $\pm 0.1 \%$ \\
\hline Heat Flux & $11-12 \mathrm{~kW} / \mathrm{m}^{2}$ & $\pm 0.5 \%$ \\
\hline Heat Transfer Coefficient & $\begin{array}{c}3.3-5.5 \\
\mathrm{~kW} / \mathrm{m}^{2}-\mathrm{O}^{\circ} \mathrm{C}\end{array}$ & $\pm 6.0 \%$ \\
\hline Pressure Drop & $2.2-8 \mathrm{kPa} / \mathrm{m}$ & $\pm 0.5 \%$ \\
\hline
\end{tabular}

Table 3.1 Initial conditions of an Evaporator

Table 3.1 depicts initial conditions of an evaporator. Measured or calculated variable for initial condition for evaporator are as follows. Range of refrigerant temperature for humidity or saturation is between $4^{\circ} \mathrm{C}$ and $9^{\circ} \mathrm{C}$. Uncertainty of refrigerant temperature for saturation was between $\pm 0.2^{\circ} \mathrm{C}$. Range of surface temperature is between $4^{\circ} \mathrm{C}$ and $21^{\circ} \mathrm{C}$. Uncertainty of surface temperature is $\pm 0.1^{\circ} \mathrm{C}$. Range of refrigerant mass flux is $250 \mathrm{~kg} / \mathrm{m}^{2} \mathrm{~s}$. Range of refrigerant mass flux is $\pm 0.1 \%$. Range of heat flux is 11 to $12 \mathrm{~kW} / \mathrm{m}^{2}$. Uncertainty of heat flux is $\pm 0.5 \%$. Range of heat transfer co-efficient $(R 410-A)$ is $3.3-5.5 \mathrm{~kW} / \mathrm{m}^{20} \mathrm{C}$. Uncertainty of heat transfer co-efficient $(\mathrm{R} 410-\mathrm{A})$ is $\pm 6 \%$. Range of pressure drop is $2.2-8 \mathrm{kPa} / \mathrm{m}$. Uncertainty of pressure drop is $\pm 0.5 \%$.

\begin{tabular}{|c|c|c|}
\hline Thermo property & R134a & R1234yf \\
\hline Chemical name & $\begin{array}{c}1,1,1,2- \\
\text { Tetrafluoroethance }\end{array}$ & $\begin{array}{c}2,3,3,3- \\
\text { Tetrafluropropene }\end{array}$ \\
\hline Chemical formula & CH2FCF3 & CF3CF=CH2 \\
\hline Boiling point at 1 atm & 247.08 & 243.7 \\
\hline Freezing point (K) & 162.3 & 169.85 \\
\hline Molar mass & 114.04 & 102.03 \\
\hline $\begin{array}{c}\text { Critical Temp (K) } \\
\text { Critical Pressure } \\
(\mathrm{Mpa})\end{array}$ & 367.15 & 373.89 \\
\hline \begin{tabular}{c} 
Critical denisty $\left(\mathrm{kg} / \mathrm{m}^{3}\right)$ \\
\hline $\begin{array}{c}\text { Vapour density } \\
\left(\mathrm{kg} / \mathrm{m}^{3}\right)\end{array}$
\end{tabular} & 367.15 & 373.89 \\
\hline
\end{tabular}

\section{Table 3.2 Material Property}

Table 3.2 illustrates material property of R134a and R1234yf. Chemical name of R134a is 1,1,1,2- Tetraflouroethane, $\mathrm{R} 1234 \mathrm{yf}$ is 2,3,3,3-Tetrafluoropropene. Chemical formula of $\mathrm{R} 134 \mathrm{a}$ is $\mathrm{CH}_{2} \mathrm{FCF}_{3}$. Chemical formula of $\mathrm{R} 1234 \mathrm{yf}$ is $\mathrm{CF}_{3} \mathrm{CF}=$ $\mathrm{CH}_{2}$. Boiling point at $1 \mathrm{~atm}$ of $\mathrm{R} 134 \mathrm{a}$ is 247.08 . Boiling point at $1 \mathrm{~atm}$ of $\mathrm{R} 1234 \mathrm{yf}$ is 243.7. Freezing point $(\mathrm{k})$ of $\mathrm{R} 134 \mathrm{a}$ is 162.3. Freezing point ( $k$ ) of R1234yf is 169.85. Molar mass of R134a is 114.04. Molar mass of R1234yf is 169.85 . Critical temp (k) of $R 134 a$ is 367.15 . Critical temp (k) of R1234yf is 373.89 . Critical pressure (Mpa) of R134a is 3.38. Critical pressure (Mpa) of R1234yf is 4.06 . Critical density $(\mathrm{kg} / \mathrm{m} 3)$ of $R 134 \mathrm{a}$ is 473.09 . Critical density $(\mathrm{kg} / \mathrm{m} 3)$ of $R 1234 \mathrm{yf}$ is 511.89. Vapour density $(\mathrm{kg} / \mathrm{m} 3)$ of $R 134 a$ is 9.81 . Vapour density $(\mathrm{kg} / \mathrm{m} 3)$ of R1234yf is 12.07 .

\section{Discussion and Results:}

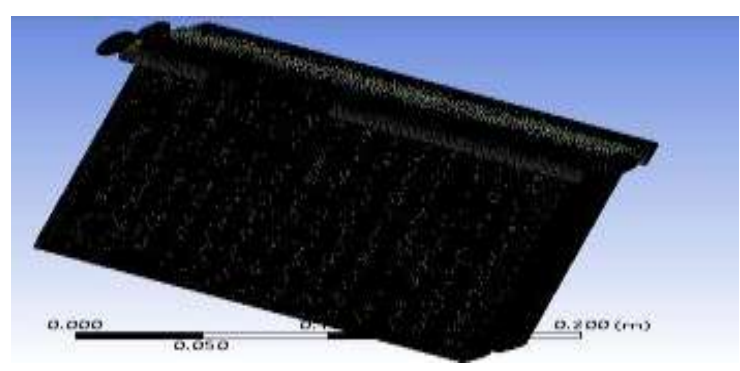

Fig 4.1 Mesh with full body 


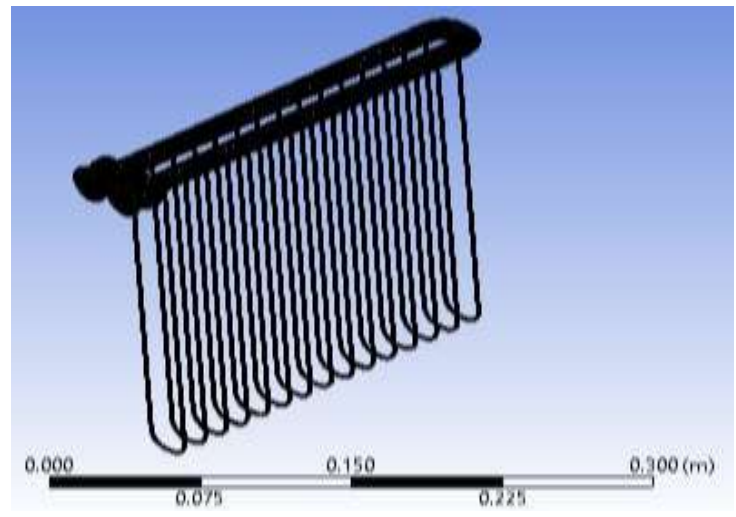

Fig 4.2: Mesh with Pipe Channel

Figure 4.3 depicts the setup model of inlet and outlet. Red indicates the inlet of the setup model. Blue indicates outlet of the setup model. Water deviation in inlet is $6.24^{-2}$ and outlet water obtains a temperature of $17.3^{\circ} \mathrm{C}$ with deviation of $2.65 \mathrm{e}-$ 02 .

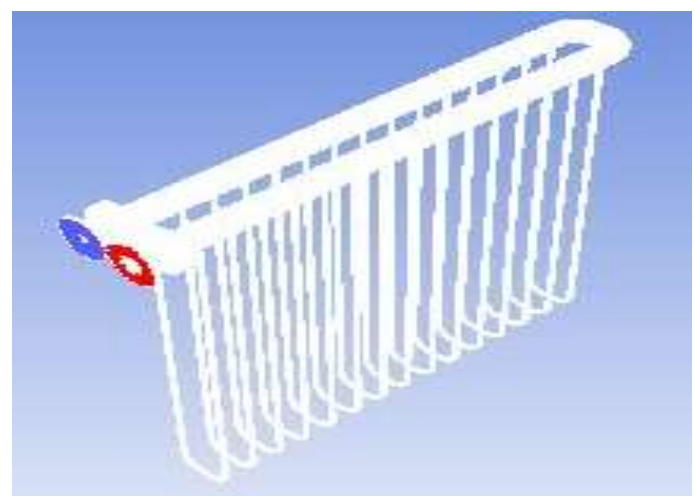

Fig 4.3: Setup model Figure

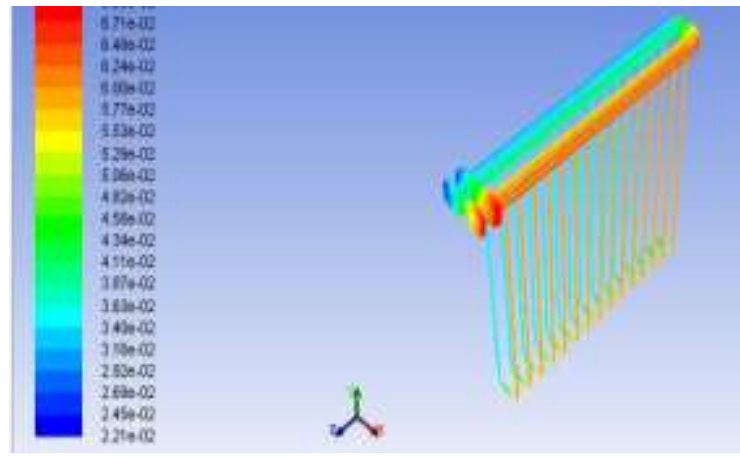

Fig 4.4: Streamline Deviation

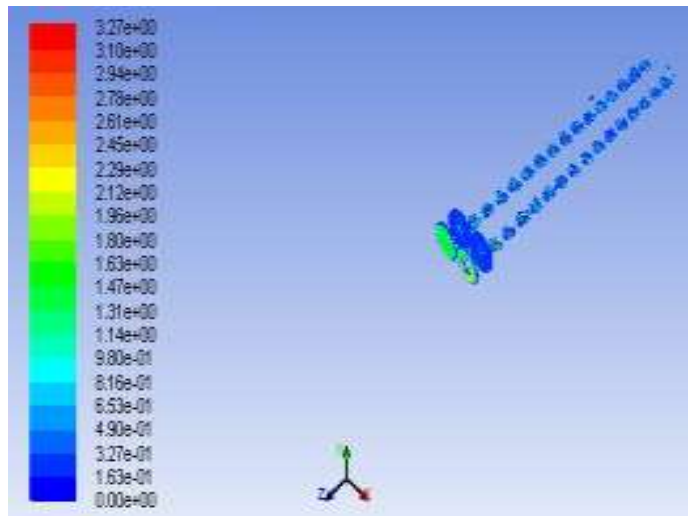

Fig 4.5: Velocity Magnitude for R1234yf 


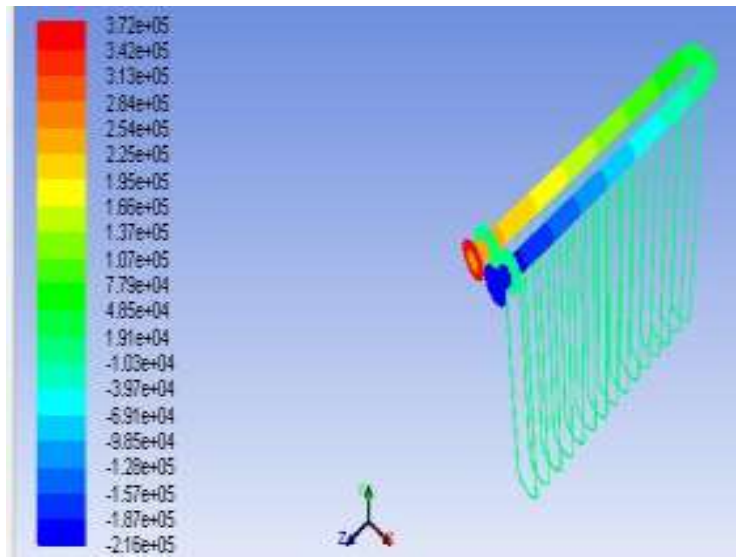

Fig 4.6: Static Pressure of fluid analysis

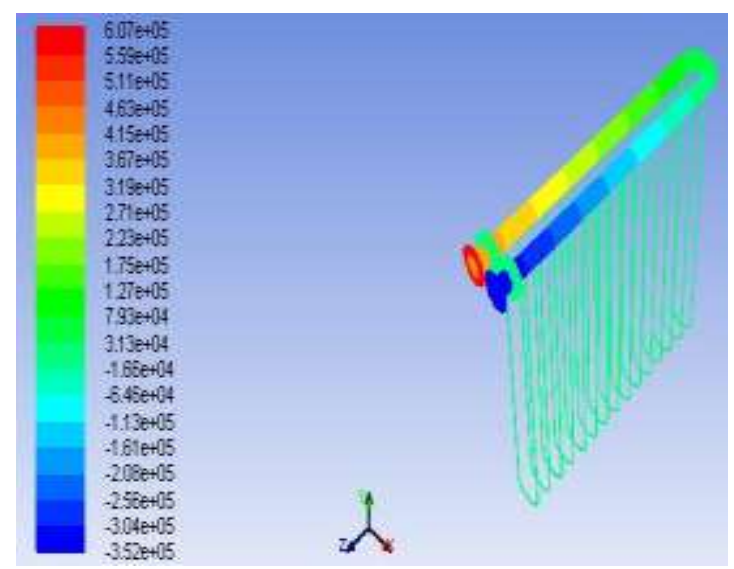

Fig 4.7: Pr. Coefficient of fluid analysis

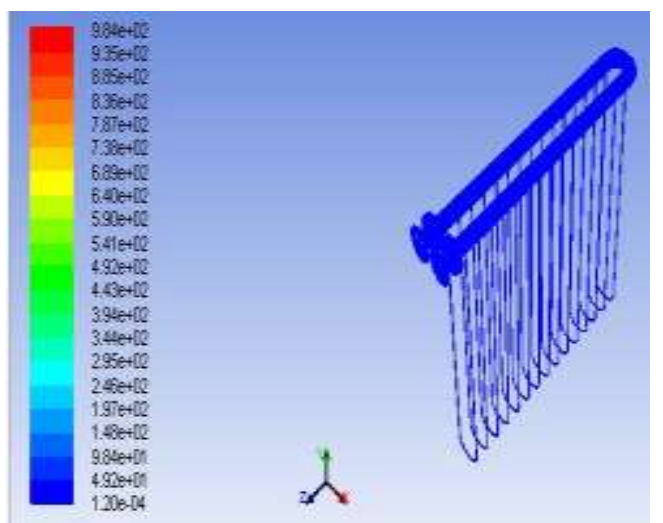

Fig 4.8: Turbulent KE of fluid analysis

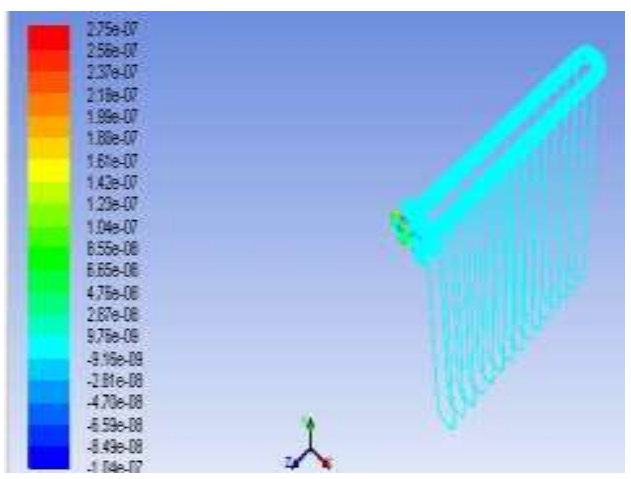

Fig 4.9: Residual Effect of fluid analysis 


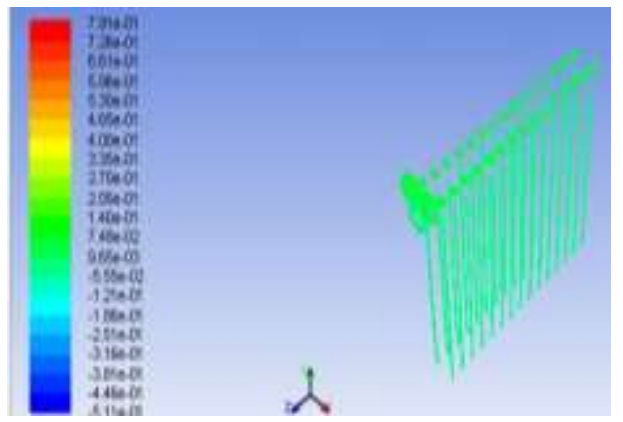

Fig 4.10: Y Axis Effect Velocity R-1234yf

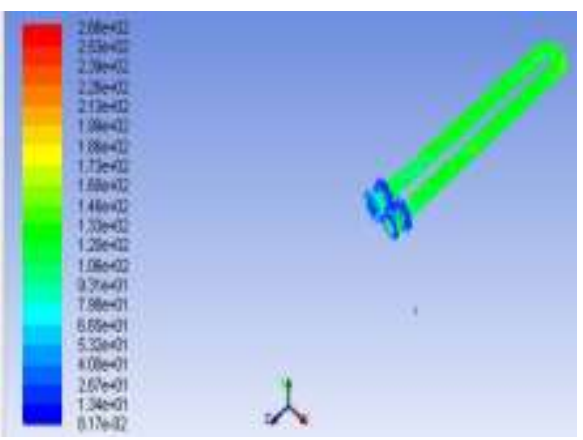

Fig 4.11 Reynolds Number in R1234yf

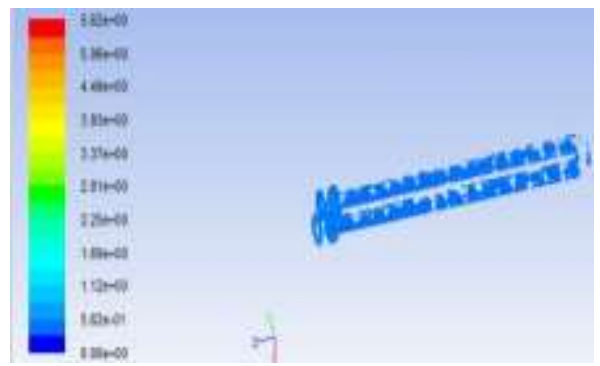

Fig 4.12: Velocity Magnitude for R134a

\begin{tabular}{|c|c|c|}
\hline SETUP & \multicolumn{2}{|c|}{ REFRIGERANT } \\
\hline INPUT & R134a & R1234yf \\
\hline Saturated Suction Temp (K) & 280.4 & 280.4 \\
\hline $\begin{array}{c}\text { Saturated Discharge Temp } \\
\text { (K) }\end{array}$ & 370 & 370 \\
\hline Cooling Capacity (W) & 10100.7 & 10100.7 \\
\hline Volumetric Efficiency (\%) & 90 & 90 \\
\hline Volume friction & 0.02 & 0.02 \\
\hline Number of Eulerian phase & 2 & 2 \\
\hline Solution mehtod scheme & Coupled & Coupled \\
\hline Flow Courant number & 25 & 25 \\
\hline Slip Velocity & 0.4 & 0.4 \\
\hline Turbulent Kinetic Energy & 0.8 & 0.8 \\
\hline
\end{tabular}

Table 4.1 Input of Refrigerants

According to the table 4.1, saturated suction temp (k) of R134a, R1234yf is $280.4^{\circ} \mathrm{C}$ Saturated discharge temp (k) of $\mathrm{R} 134 \mathrm{a}, \mathrm{R} 1234 \mathrm{yf}$ is $370^{\circ} \mathrm{C}$. Cooling capacity (W) of R134a, R1234yf is 10100.7 . Volumetric efficiency (\%) of R134a, R1234yf is 90 . Volume friction of R134a, R1234yf is 0.02 . Number of eulerian phase of R134a, R1234yf is 2. Solution 
method scheme for R134a, R1234yf is coupled. Flow courant number of R134a, R1234yf is 25. Slip velocity of R134a, $\mathrm{R} 1234 \mathrm{yf}$ is 0.4 . Turbulent kinetic energy of R134a, R1234yf is 0.8 .

\begin{tabular}{|c|c|c|}
\hline SETUP & \multicolumn{2}{|c|}{ REFRIGERANT } \\
\hline INPUT & R134a & R1234yf \\
\hline Saturated Suction Temp (K) & 280.4 & 280.4 \\
\hline Saturated Discharge Temp (K) & 370 & 370 \\
\hline Cooling Capacity (W) & 10100.7 & 10100.7 \\
\hline Volumetric Efficiency (\%) & 90 & 90 \\
\hline Suction Pressure (Pa) & 23479.2 & 23472.3 \\
\hline Discharge Pressure (Pa) & 1371621 & 1370891 \\
\hline COP (Cooling) & 3.69 & 1.31 \\
\hline Refrigerant side Pr. Drop - Fin & 6127 & 8096 \\
\hline Avg Ref. Outlet Temp (K)-Fin & 378 & 371 \\
\hline Refrigerant side Pr. Drop - Tube & 1073.6 & 1072.8 \\
\hline Avg Ref. Outlet Temp (K)-Tube & 371 & 370 \\
\hline
\end{tabular}

Table 4.2 Results of Refrigerants

In the table 4.2, it was noticed that saturated suction temp (k), saturated discharge temp (k), cooling capacity (W), volumetric efficiency (\%) was same as the input. Suction pressure (Pa) of R134a was 23479.2, R1234yf was 23472.3 . Discharge pressure $(\mathrm{Pa})$ of $\mathrm{R} 134 \mathrm{a}$ was 1371621 . Discharge pressure $(\mathrm{Pa})$ of R1234yf was 1370891. COP (cooling) of $\mathrm{R} 134 \mathrm{a}$ was 3.69. COP (cooling) of R1234yf was 1.31. Refrigerant side pressure drop (Pa) of fin for R134a was 6127 . Refrigerant side pressure drop (Pa) of R1234yf was 8.096. Average refg outlet temp $(\mathrm{k})$ for fin of R134a was 378 . Average refg outlet temp (k) for fin of R1234yf was 371. Refrigerant side pressure drop (Pa) for micro-channel of R134a was 1073.6. Refrigerant side pressure drop $(\mathrm{Pa})$ for micro-channel of R1234yf was 1072.8. Average refg outlet temp (k) for micro-channel of R134a was 371. Average refg outlet temp (k) for micro-channel of R1234yf was 370.

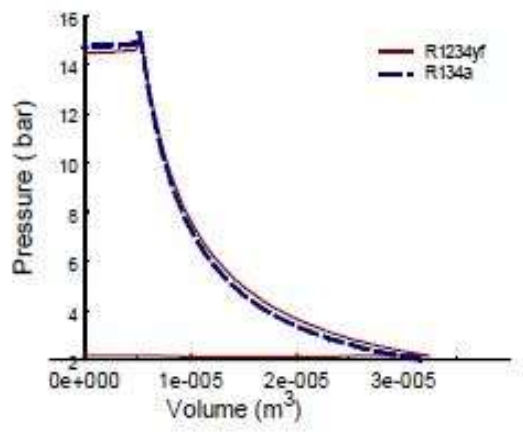

Figure 4.13: Pressure of Refrigerants

In the figure 4.13,. blue colour depicts the pressure of R134a. Red colour depicts the pressure of R1234yf.

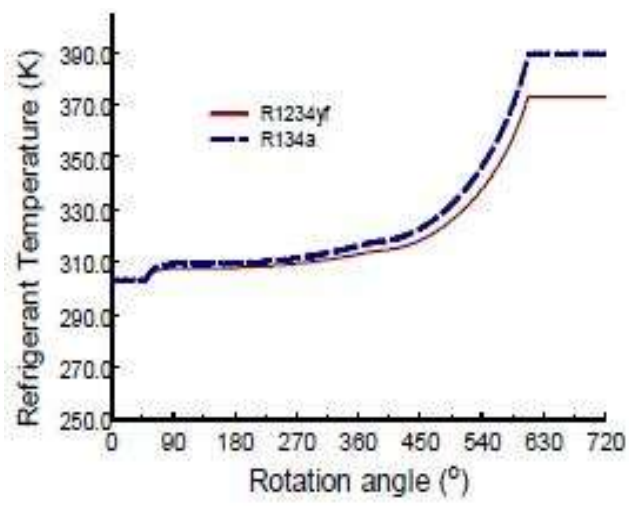

Figure 4.14 Refrigerant Temperature 
In the figure 4.14, blue colour depicts the refrigerant temperature of R134a. Red colour depicts the refrigerant temperature of R1234yf. It was clear that refrigerant temperature of R134a was better than R1234yf.

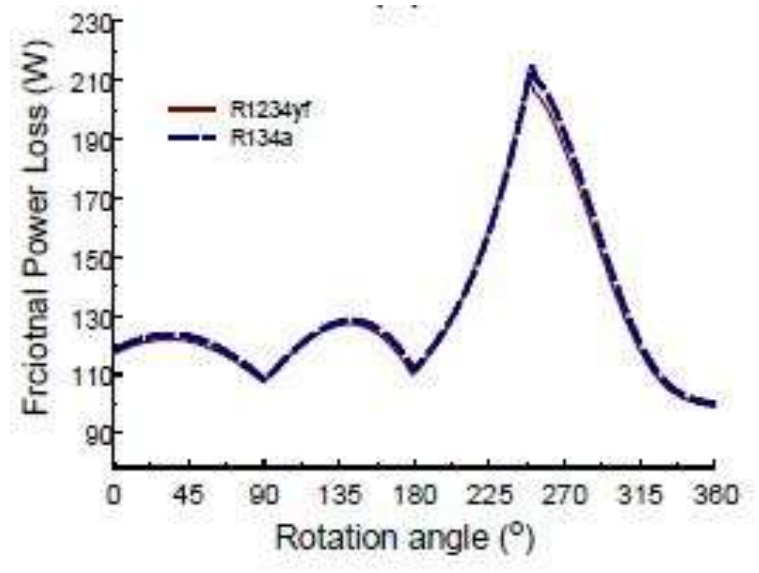

Figure 4.15: Frictional Power Loss (W)

In Figure 4.15, , blue colour depicts the frictional power loss of R134a. Red colour depicts the frictional power loss of R1234yf.

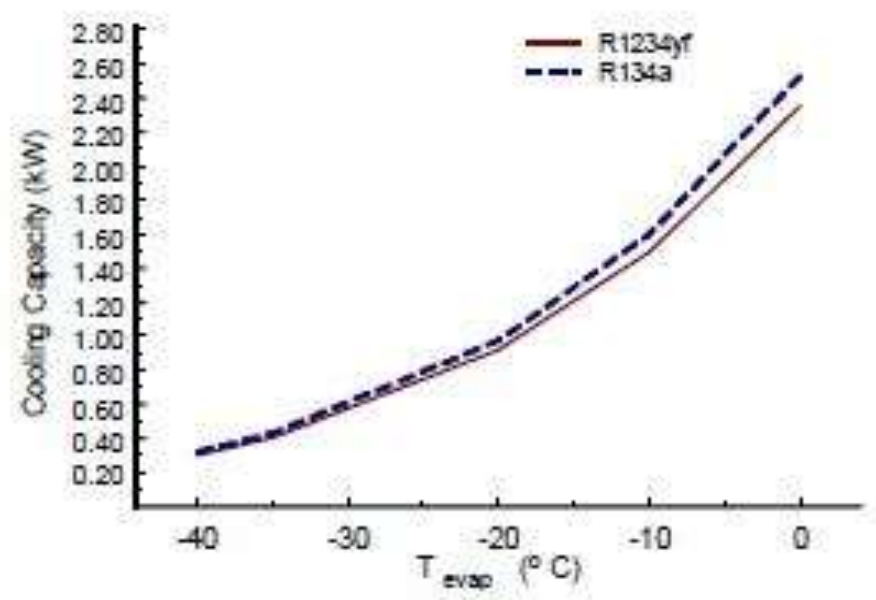

Figure 4.16 Cooling Capacity (kW)

In figure 4.16, blue colour indicates the cooling capacity of R134a. Red colour indicates the cooling capacity of R1234yf. The cooling capacity of R134a was better than R1234yf.

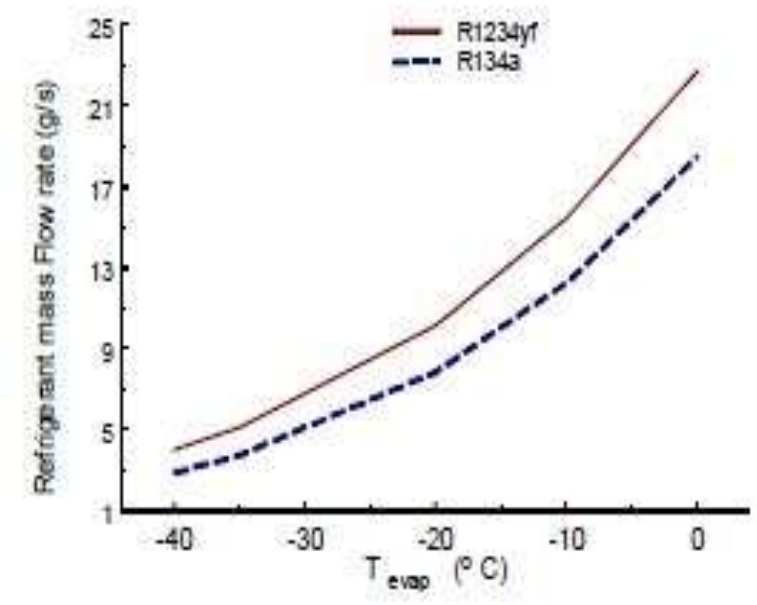

Figure 4.17 Refrigerant mass flow rate $(\mathrm{g} / \mathrm{s})$ 
In Figure 4.17 blue colour indicates the refrigerant mass flow rate $(\mathrm{g} / \mathrm{s})$ of R134a. Red colour indicates the refrigerant mass flow rate $(\mathrm{g} / \mathrm{s})$ of R1234yf. It was clear that refrigerant mass flow rate $(\mathrm{g} / \mathrm{s})$ of R134a was steady when compared with R1234yf.

\section{Conclusion and Future Work:}

Purpose of the research is to conduct two-phase fluid analysis on examining influence of refrigerant (R134a/R1234yf) properties on cooling performance of an automobile heating, ventilation and air conditioning evaporator core and compare their performance.

It was noticed that saturated suction temp (k), saturated discharge temp (k), cooling capacity (W), volumetric efficiency (\%) was same as input. Output values of the refrigerant are as follows:

Suction pressure (Pa) of R134a was 23479.2, R1234yf was 23472.3.

Discharge pressure (Pa) of R134a was 1371621, R1234yf was 1370891.

COP (cooling) of R134a was 3.69, R1234yf was 1.31.

Refrigerant side pressure drop (Pa) of fin for R134a was 6127, R1234yf was 8.096.

Average refg outlet temp (k) for fin of R134a was 378, R1234yf was 371. Refrigerant side pressure drop (Pa) for microchannel of R134a was 1073.6, R1234yf was 1072.8. Average refg outlet temp (k) for microchannel of R134a was 371, R1234yf was 370. By conducting streamline deviation, static pressure, velocity magnitude, pressure coefficient, turbulent kinetic energy for refrigerant R1234yf and R134a. It was shown that R134a properties were better than R1234yf.

The simulations and two-phase fluid analysis determined thatR134a was a feasible idea than R1234yf towards the cooling performance of an automobile HVAC evaporator core.

Extensive study can be carried out on other refrigerants i.e., R410a and R22. Comparison of their performances in the cooling of the automobile HVAC evaporator core.

\section{References:}

1. Hrnjak, P., Litch, A.D., 2008. Microchannel heat exchangers for charge minimization in air-cooled ammonia condensers and chillers, International Journal of Refrigeration31, 658-668.

2. Incropera, F.P., DeWitt, D.P., Bergman, T.L., Lavine, A.S., 2006. Fundamentals of Heat and Mass Transfer. John Wiley \& Sons, Hoboken, NJ

3. Sanaye and M. Dehghandokht, (2012) "Thermal Modeling of Mini-Channel and Laminated Types Evaporator in Mobile Air Conditioning System", International Journal of Automotive Engineering, Vol. 2, No. 2

4. Radermacher, R., Yang, B., Hwang, Y., 2007. Integrating Alternative And Conventional Cooling Technologies, ASHRAE Journal, October 2007, 28-35

5. Reasor.P et al (2010), Refrigerant R1234yf Performance Comparison Investigation, International Refrigeration and Air Conditioning Conference.

6. Potkler.G and Hrnjak.S (2012), Effect of Condenser Sub-cooling of the Performance of Vapor Compression Systems: Experimental and Numerical Investigation, International Refrigeration and Air Conditioning Conference.

7. Yohan Lee, Dongsoo Jung, "A brief performance comparison of R1234yf and R134a in a bench tester for automobile applications", Applied Thermal Engineering 35 (2012) 240-242

8. Gomaa.A (2015), Performance Characteristics of Automotive Air Conditioning System with Refrigerant R134a and its Alternatives, IJEPE, 4(3), 168-177

9. Gaurav and Kumar. R (2015), Environmental Sustainability of Automobile AIR-conditioning System with Refrigerant R1234yf, IJARI, vol 3, issue 4. 